\title{
Risco Ambiental e Contextos Vulneráveis: Implicações para a Vigilância em Saúde
}

\author{
Environmental Risk and Vulnerable Contexts: Implications \\ on Health Surveillance
}

\author{
Lia Giraldo da Silva Augusto \\ Centro de Pesquisas Aggeu Magalhães/FIOCRUZ
}

Carlos Machado de Freitas

Escola Nacional de Saúde Pública/FIOCRUZ

João Paulo Machado Torres

Laboratório de Biofísica/FIOCRUZ

\begin{abstract}
Resumo
Este artigo procura traduzir para o público em geral o resultado de um seminário realizado, em Recife, no ano de 1999, na preparação do I Seminário Nacional de Saúde e Ambiente no Processo de Desenvolvimento, realizado em 2000, pela Fundação Oswaldo Cruz (Fiocruz), na cidade do Rio de Janeiro. Foram convidados três intelectuais (da geografia, da saúde e da filosofia) para falar sobre risco ambiental para a saúde. Suas perspectivas foram articuladas pelos autores para compor um termo de referência para a discussão do Grupo de Trabalho que debateu o tema "avaliação de risco ambiental e vigilância em saúde". O seminário possibilitou o debate sobre os conceitos de risco (ambiental) e de causalidade, bem como suas implicações para a avaliação, monitoramento e prevenção em saúde. Ofereceu novas perspectivas conceituais para a compreensão da causalidade, à luz da abordagem da complexidade, e introduziu a perspectiva da interdisciplinaridade no fazer da vigilância em saúde ambiental, em situações de vulnerabilidade, tal como a seca no Nordeste brasileiro. Também, apresentou o método da matriz de dados, para tratar uma problemática socioambiental em seu contexto.
\end{abstract}

\section{Palavras-Chave}

Risco; Ambiente; Contexto.

\section{Summary}

This article summarizes the results of a seminar held at Recife in 1999 during the preparatory activities conducted by the Oswaldo Cruz Foundation (Fiocruz) for the " $1{ }^{\text {st }}$ National Seminar on Environment and Health in the Process of Development" which was held in Rio de Janeiro in 2000. Three renowned experts in the fields of Geography, Health and Philosophy areas were invited to discuss environmental risk and health, and their perspectives were used as a basis for a reference text which served as a background document for dicussion of the seminar's working group debating the theme "environmental risk and health surveillance". The workshop allowed a discussion of the concepts of environmental risk and causality as well as, the implications on health evaluation, monitoring and prevention. New conceptual perspectives to comprehend casuality in the context of complexity were discussed and an interdisciplinary approach was introduced to environmental health surveillance, particularly for vulnerable situations, such as the drought in northeastern Brazil. A data matrix was presented to be used in the analysis of social and environmental problems.

Key Words

Risk; Environment; Context.

Endereço para correspondência: Rua Ministro Nelson Hungria, 266 - Apto 201 - Boa Viagem - Recife/PE. CEP: 51.020-100.

E-mail: giraldo@cpqam.fiocruz.br

Informe Epidemiológico do SUS 2002; 11(3) : 155 - 158. 


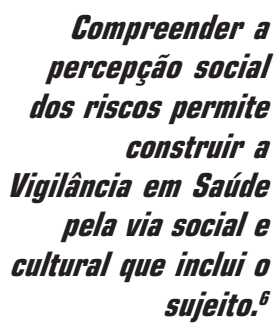

sujeito. ${ }^{6}$

\section{Introdução}

O conceito de risco utilizado no campo da saúde coletiva está ligado aos fatores de risco como determinantes dos processos saúde-doença e é um conceito da Epidemiologia Moderna, ${ }^{1}$ que busca determinar probabilisticamente a causalidade. No entanto, para a compreensão do processo saúde-doença, a abordagem clássica dos fatores de risco não é suficiente como um modelo explicativo.

Partir da conceituação de risco para posteriormente dar-lhe conseqüência, não é tarefa simples. A saúde deve ser entendida em sua dimensão global, cujo enfoque é o da pluricausalidade, reconhecendo-se de antemão que os elementos bio-sócio-ambientais e produtivos relacionam-se de maneira interdependente e interdefinível, conferindo-lhe um caráter complexo. ${ }^{2}$

A seca do Nordeste brasileiro é um problema perene que precisa ser compreendido, não só na ocasião em que se manifesta. Implica também reconhecer que o elemento espacial-territorial, isto é, o ambiente físico é também histórico e culturalmente determinado. Dessa forma, retiramos de antemão todo e qualquer fatalismo e conformismo ao tratar a questão da seca. O objetivo do seminário preparatório do I Seminário Nacional da Saúde e Ambiente no Processo de Desenvolvimento foi discutir o conceito de risco ambiental e sua aplicabilidade aos programas de prevenção em saúde, considerando determinados contextos. Escolhemos a problemática da seca que aflige periodicamente o Nordeste brasileiro por seu significado social e histórico.

\section{Pesquisadores}

Contamos com a participação de importantes pesquisadores que vêm refletindo a temática proposta para o seminário. Assim, para tratar o contexto da seca, convidamos Manoel Corrêa de Andrade, geógrafo e pesquisador da Fundação Joaquim Nabuco, de Pernambuco.

Para a questão da vigilância em saúde ambiental, do monitoramento e prevenção de risco em contextos vulneráveis, contamos com o aporte teórico de Renato Rocha Lieber, pesquisador da Universidade do Estado de São Paulo (UNESP), campus de Guaratinguetá.

Nas questões metodológicas aplicadas à complexidade das situações de risco ambiental para a saúde, propusemos refletir sobre a perspectiva da abordagem sistêmica. Para esse aporte teóricometodológico, convidamos Juan Samaja, filósofo e professor de metodologia da ciência, da Universidade de Buenos Aires, que apresentou as bases teórico-conceituais dos sistemas complexos (hierárquicos adaptativos) e o método por ele desenvolvido da matriz de dados.

\section{Discussão}

Segundo Manoel Correia de Andrade, ${ }^{3}$ a seca tem suas bases físicoclimáticas e suas razões sociopolíticas. Essa é uma situação que, pelas proporções que toma, tem importância nacional, sendo um problema de todos e, portanto, uma questão transdisciplinar. No Brasil, esse é um tema sempre atual. Em sua história, são recorrentes a falta de água, as perdas de produção, a emigração e o flagelo humano.

Onde há sofrimento humano, vale dizer que há menos saúde e, com esse entendimento, deveria haver uma preocupação específica da Saúde Pública brasileira com as populações das regiões semi-áridas.

Diante dos desafios que se apresentam nesse contexto, a análise deveria comportar a complexidade em sua determinação histórica. É uma possibilidade para explicar o comportamento humano, quer seja das populações ou dos governos, na construção das estratégias de intervenção que objetivam o desenvolvimento social.

As vítimas da seca não podem ser entendidas como aquelas que decidiram viver num ambiente inóspito e, por isso, o fizeram por um risco mal calculado. ${ }^{4}$

O problema da aceitação do risco, em geral, é atribuído a funções antagônicas, tais como inteligência ou má 
decisão. Essas compreensões simplistas têm sido questionadas.

O ajuste do homem ao ambiente hostil, sua percepção da nocividade, sua adaptação às condições perigosas e a solução do seu conflito entre riscos e benefícios são decorrentes de um nexo entre fatores sociais e suas relações complexas com o ambiente, mediados pelos processos produtivos, pela cultura, pela religião e pela história.

Em conformidade com o contexto social, o homem apresenta determinadas atitudes com relação aos meios de sobrevivência, além de diferentes possibilidades de tomada de decisão e de controle sobre suas vidas. ${ }^{5}$

Os programas de vigilância epidemiológica e de monitoramento ambiental têm estado distante das possibilidades de interpretação sistêmica e foi nesse sentido, o de contribuir para a mudança de abordagem, que propusemos essa reflexão.

O foco das vigilâncias (sanitária e epidemiológica) na Saúde Pública brasileira continua tradicionalmente sendo o indivíduo, como se a esse nível fosse possível exercer o controle dos riscos ambientais para a saúde.

Pelo contrário, compreender a percepção social dos riscos, permite-nos entender os processos complexos, com a possibilidade de construir a Vigilância em Saúde pela via social e cultural que inclui o sujeito. ${ }^{6}$ A percepção de risco representa uma dimensão subjetiva, em contraste com a dimensão objetiva, conferida pela estimativa da probabilidade. ${ }^{7}$

Desde o estudo do processo de decisão até o estudo da natureza da percepção do risco, a vítima e a sua vontade nunca deixaram de ser o elo central de articulação das possibilidades e, portanto, das medidas de controle. ${ }^{8}$

Uma outra alternativa a essa tendência ${ }^{9}$ toma como base empírica os acidentes, e defende que a maioria deles são decorrentes de um comportamento rotineiro. ${ }^{10}$ Como regra, as vítimas encontram-se sob risco, mas isso não implica que elas estejam sendo levadas a lhe dar atenção ou ter consciência a seu respeito. Elas são colocadas em situações de risco por outras pessoas ou organizações. Consequientemente, as ações de promoção, controle e comunicação deveriam ser dirigidas não às possíveis vítimas, mas sim àqueles que nas organizações e na sociedade tomam as decisões que vão criar, agravar ou manter situações inseguras. Ou seja, a vítima é vítima mediante uma vontade alheia. ${ }^{11}$ Essas são algumas das teorias sobre risco que vêm sendo discutidas e está clara a necessidade de se fazer análise de risco em diferentes níveis, revendo as práticas quantitativas de risco, substituindo o caráter fatalista destes por uma aproximação holística. ${ }^{12}$

A perspectiva da incerteza e da complexidade é, hoje, um enfoque essencial e necessário. ${ }^{13,14}$ A utilização da matriz de dados, ${ }^{15}$ com suas unidades de análise, variáveis e indicadores estruturados em níveis hierárquicos e interdependentes, é uma ferramenta que possibilita o enfoque da complexidade.

Toda a investigação clássica da causalidade, seja num processo de pesquisa científica, seja num programa de monitoramento ambiental ou vigilância em saúde, está presa a uma razão explicativa, obrigando-se a reduzir o novo a um antigo (as causas). As regras lógicas, em geral, estão voltadas para esconder, ao invés de ressaltar, a singularidade paradoxa. ${ }^{6}$ A tradição da Saúde Pública é muito amarrada na perspectiva de pensar sobre as possibilidades de medir riscos pelo sistema de vigilância epidemiológica para implementação de ações de prevenção e controle.

\section{Considerações finais}

Partindo do pressuposto de que as mudanças não se dão por achar respostas para velhas questões, mas por formular novas perguntas para velhos problemas, o debate deixou como conclusão algumas questões para futuras reflexões. A primeira, uma indignação, refere-se ao fato de a condição humana, cuja racionalidade não é de forma alguma absoluta, 
ser "sintetizada" por sistemas de monitoramento de formato absoluto. As demais questões podem ser assim resumidas: por que a perspectiva tecnológica, que tem sido tão capaz na criação de mundos artificiais, na dominação da natureza, tem sido tão incompetente na esfera das relações humanas? Qual é o limite do homem diante da natureza? Como o controle de riscos, que também é uma construção cultural, pode ser aplicado em favor da saúde e da qualidade de vida?

\section{Referências bibliográficas}

1. Rouquayrol MZ. Epidemiologia, história natural e prevenção de doenças. In: Rouquayrol MZ. Epidemiologia e saúde. $4^{a}$ ed. São Paulo: Medsi; 1994.

2. Garcia R. Interdisciplinaridad y sistemas complexos. In: Leff $\mathrm{H}$, compilador. Ciencias sociais y formación ambiental. Barcelona: Gedisa; 1994.

3. Andrade MC. A terra e o homem no Nordeste. Recife: Universidade Federal de Pernambuco; 1998.

4. Cruz T. Sistemas, organização e métodos: estudos integrados das novas tecnologias de informação. São Paulo: Atlas; 1997.

5. Damasio AR. O erro de Descartes: emoção, razão e o cérebro humano. São Paulo: Companhia das Letras; 1996.

6. Lieber RR. Teoria e metateoria na investigação da causalidade: o caso do acidente de trabalho [tese de Doutorado]. São Paulo (SP): USP; 1998.

7. Dejours C. Trabalho e saúde mental: da pesquisa a ação. In: Dejours C, Abdoucheli E, Jayet C. Psicodinâmica do trabalho. São Paulo: Atlas; 1994.

8. Dela-Coleta JA. Atribuições de responsabilidade por um acidente: estudo exploratório. Arquivos Brasileiros de Psicologia 1980;3(1):95-128.

9. Crespi F. Le risque du quotidien. Cahiers Internationaux de Sociologie 1983;30(74):39-45.

10. Dela-Coleta JA. A importância da seleção e do treinamento do trabalhador na prevenção de acidentes. Revista Brasileira de Saúde Ocupacional 1976; 16(4):48-51.

11. Dela-Coleta JA. Acidentes de trabajo. Medelin: Ancel; 1991.

12. Burgoyne JH. Reflections on accident investigation. Safety Science 1993; 16:401-406.

13. Samaja J. Epistemologia y metodologia. Buenos Aires: Eudeba; 1997.

14. Masarivo MD, Macko D. Fundamentos de una teoria científica de los sistemas jerárquicos. In: White LL, Wilson AG, White D. Las estructuras jerárquicas. Madrid: Alianza Universidad; 1973.

15. Samaja J. Fundamentos epistemológicos de las ciencias de la salud [tese de Doutorado]. Rio de Janeiro (RJ): FIOCRUZ; 1997. 